\title{
EDUCAÇÃO EM SEXUALIDADE, VIOLÊNCIA E PARTO HUMANIZADO: O QUE SABEM OS JOVENS SOBRE DIREITOS REPRODUTIVOS?
}

\author{
Maria de Fátima Salum Moreira ${ }^{1}$, Taluana Laiz Torres Martins ${ }^{2}$, Valteir Carvalho Freitas ${ }^{3}$ \\ ${ }^{1}$ Universidade do Oeste Paulista - UNOESTE. Pós-Graduação em Educação, Presidente Prudente - SP. Universidade \\ Estadual Paulista - UNESP, Pós-Graduação em Educação, Presidente Prudente - SP. ${ }^{2}$ Universidade Estadual Paulista - \\ FCT/UNESP, Doutorado em Educação, Presidente Prudente - SP. ${ }^{3}$ Universidade do Oeste Paulista - UNOESTE. Curso \\ de Psicologia, Presidente Prudente - SP. Email: fatimasalum@gmail.com
}

\section{RESUMO}

Este artigo discute a educação em sexualidade para jovens que, frequentemente, é abordada em um viés biologicista, focado na reprodução humana e na gravidez nesta fase da vida, a qual é considerada um "problema". São abordados temas como: a) marcos dos direitos reprodutivos e sua importância para inserção do tema em projetos educativos, b) surgimento do ECA e relação com o tema, c) controle e violência exercidos sobre a mulher pela ciência obstétrica e a ginecologia, d) significado e importância das lutas pelo parto humanizado. Pretende-se apontar temáticas e questões necessárias ao tratamento da educação em sexualidade de jovens que não são contempladas em propostas educativas, para que possam ganhar uma visão mais ampla e positiva de sua sexualidade, buscando vivê-la de forma autônoma e responsável. Propõe-se uma educação que lhes permita reconhecerem quais são os seus direitos reprodutivos, especialmente aqueles relacionados ao momento anterior e posterior ao parto.

Palavras-chave: Direitos reprodutivos, Parto Humanizado, Jovens, Educação, Sexualidade

\section{EDUCATION IN SEXUALITY, VIOLENCE AND HUMANIZED BIRTH: WHAT TO KNOW THE YOUTH ABOUT REPRODUCTIVE RIGHTS?}

\begin{abstract}
This article discusses sexuality education for young people is often addressed on a biologicist bias, focused on human reproduction and pregnancy at this stage of life, which is considered a "problem". Topics are covered: a) landmarks of reproductive rights and their importance for inclusion of the topic in educational projects, b) emergence of ECA and relationship with the subject, c) control and violence exerted on women by science and obstetric gynecology, d) meaning and importance of struggles humanized birth. It is intended to themes and issues necessary for the treatment of sexuality education for young people that are not addressed in educational proposals so that they can gain a broader and more positive view of their sexuality, seeking to live it autonomously and responsibly point. Propose an education that allows them to recognize what their reproductive rights, especially those related to prior and subsequent to delivery time.
\end{abstract}

Keywords: Reproductive rights, Humanized Birth, Youth, Education, Sexuality 


\section{INTRODUÇÃO}

A discussão da reprodução humana e dos problemas da gravidez na juventude tem sido a tônica principal da educação em sexualidade para jovens. Costumeiramente, isso é feito através do ensino de conteúdos vinculados ao funcionamento do corpo biológico e reprodutivo, cujas bases teóricas são relacionadas ao determinismo biológico.

Contudo, tal problemática tem sido parcialmente tratada de modo que são parcas as condições oferecidas aos jovens para o exercício autônomo, esclarecido e responsável em relação ao direito em tomar decisões quanto a maternidade ou paternidade, bem como sobre as demais questões relacionadas a tais escolhas. Em vista disso, iremos apresentar, neste trabalho, uma face pouco abordada no tema. Trataremos, mais especificamente, das ações necessárias a uma formação fundamentada no conhecimento dos elementos históricos, sociológicos e culturais, que produzem os saberes e as práticas de violência relacionadas a gravidez, o parto e pós-parto. Aludimos, portanto, a questões que comparecem de forma marginal em estudos e políticas da educação e saúde. Em vista disso, não se observam estudos acadêmicos que resultem na produção de outros olhares e propostas educativas que consideram os jovens como agentes capazes de elaborar projetos de vida ou de agir com responsabilidade. E, fundamentalmente, que proporcionem ações pedagógicas que lhes ofereçam as condições para reconhecer a violação de seus direitos em práticas envolvidas com discriminação ou coerção, reveladoras das diversas formas de violência física, psíquica e emocional (MOREIRA et.al., 2013).

$\mathrm{Na}$ primeira parte do texto apresentamos os principais marcos dos direitos reprodutivos, com destaque para a importância da inserção deste tema em projetos educacionais voltados a sexualidade dos jovens. Em seguida, são explicitadas as discussões sobre a violência obstétrica e, em contrapartida, aquelas sobre o parto humanizado para, finalmente, tematizar e problematizar as implicações de sua ausência nos projetos de ensino e conteúdos escolares, bem como as contradições e lacunas que se encontram na educação voltada à sexualidade dos jovens.

\section{DIREITOS REPRODUTIVOS E EDUCAÇÃO ESCOLAR}

Os direitos reprodutivos são compreendidos como parte integral e também como uma ampliação da noção dos direitos humanos (SCAVONE, 2004, p.55). Compreendemos, portanto, que os direitos reprodutivos são constituídos por "princípios e normas de Direitos Humanos que garantem o exercício individual, livre e responsável da sexualidade e da reprodução humana" (VENTURA, 2009, p.19). Trata-se do direito de toda pessoa decidir sobre o número de filhos e os intervalos entre os nascimentos, além de ter acesso aos meios necessários para o exercício livre de 
sua autonomia reprodutiva, sem sofrer discriminação, coerção ou restrição, de qualquer natureza, que implique em violência física e emocional.

Dois marcos internacionais são fundantes na definição dos direitos reprodutivos: a Conferência do Cairo sobre População e Desenvolvimento, de 1994, e a IV Conferência Mundial sobre a Mulher, Desenvolvimento e Paz, realizada em Pequim, no ano de 1995. Nas duas Conferências, a educação aparece como uma das diretrizes fundamentais visto que ela faz parte dos processos que permitem aos indivíduos se capacitar para decidirem livremente "sobre as condições em que a reprodução pode (ou não) se realizar". Isso em acordo com o ideário da "responsabilidade para consigo mesmos e para com os demais" (VIANNA; LACERDA, 2004, p.33).

A esse respeito, Tonelli (2004) ressalta que nas duas últimas décadas houve um avanço considerável nas políticas públicas voltadas para a infância e a juventude no Brasil. Nesse sentido, o Estatuto da Criança e do Adolescente (ECA - Lei n.8.069/1990), tornou-se um marco importante na legislação brasileira, afirmando que crianças e jovens são sujeitos de direitos, em suas mais diferentes condições sociais e individuais e, portanto, a condição de pessoa em desenvolvimento não deve ser um impeditivo para o exercício desses direitos. Apesar de tais avanços, o ECA não especifica claramente quais são os direitos em relação ao exercício da sexualidade dos jovens, de modo que não garante a possibilidade desses sujeitos decidirem sobre sua vida sexual e reprodutiva. Ainda com relação ao estatuto, não encontramos referências a aspectos mais amplos da sexualidade e que são diretamente vinculados às desigualdades de gênero, tais como: a discussão do prazer e do corpo erótico, os ideais românticos e amorosos, a gravidez enquanto experiência possível e o parto.

Em contrapartida, um elemento positivo que deve ser ressaltado no Estatuto da Criança e do Adolescente é o reconhecimento ao direito à privacidade e à preservação do sigilo no acesso de jovens aos serviços de saúde, posto que essa população tem o direito de ser atendida independente da autorização da família ou de responsáveis. Adiante, a lei garante que toda criança e adolescente tenha sua opinião ouvida e considerada, na perspectiva de seu melhor interesse na decisão sobre os aspectos de sua vida (VENTURA, 2009, p.276). Percebe-se que os jovens brasileiros ainda estão presos ao discurso pautado na "ilegitimidade" de sua sexualidade, entendimento que ignora seus direitos de viverem a sexualidade de forma plena. O ECA falha quando apresenta como foco a prevenção, seja da gravidez 'não planejada' ou das doenças sexualmente transmissíveis e AIDS. Parte-se da visão de uma sexualidade que deve ser 'regulada', 'cerceada', por intermédio de um discurso prescritivo e normativo que desqualifica as possibilidades de exercício da sexualidade desse grupo. 
Neste contexto, as instituições educativas têm um papel fundamental para a garantia de efetivação dos direitos reprodutivos dos jovens, pois pode participar ativamente em sua formação para a vivência de uma sexualidade com base na prática da autonomia, responsabilidade e compromisso. Segundo Cabral e Heilborn (2012) a perspectiva de Educação em Sexualidade revela a preocupação de inserir, no trabalho pedagógico com jovens, discussões que envolvem temas polêmicos, ainda considerados tabus e que não têm recebido a devida atenção, como o aborto, o planejamento reprodutivo e a contracepção, a partir da perspectiva de gênero e diversidade sexual. Entre esses, encontram-se os temas que envolvem o parto, os quais serão tratados a seguir, uma vez que esses podem atuar como forma de problematizar as mais diversas práticas de violência que muitas mulheres sofrem desde o momento da gestação.

\section{A HUMANIZAÇÃO DO PARTO E O COMBATE À VIOLÊNCIA OBSTÉTRICA}

O nascimento é um acontecimento fisiológico cujo caráter é social, cultural e histórico. Representa a continuidade da vida, sendo a ideia do nascer comemorada em várias sociedades com algum ritual de início. Em consonância, o parto e sua assistência são compreendidos enquanto um ato cultural, pois refletem os valores sociais prevalecentes historicamente em cada sociedade e costumam ser regulados por normas sociais determinadas. Deve ser compreendido como processo e produto de uma determinada sociedade e cultura. Tais relações e práticas culturais envolvem mulheres muito distintas que, além das relações de gênero, experimentam específicas determinações de classe, nacionalidade, étnico-raciais, geracionais e outras. (GAMA et al.,2009).

A experiência do parto tem sido vivida diferentemente pelas mulheres brasileiras. Em primeiro lugar, em função da diversidade social e cultural existente em um país de grande amplitude territorial, em que os marcadores sociais como classe, etnia, gênero, sexualidade e geração demandam políticas diversas e específicas, em conformidade com os valores e práticas de parto praticadas em coletividades compostas por mulheres com diferentes experiências no exercício da parturição. Em tal contexto, o gerenciamento do corpo das mulheres, pela ciência obstétrica, irá oferecer os elementos explicativos para o que é "ser mulher" com base nos ditames da natureza. Essa estaria revelada em seu corpo, que deveria ser esquadrinhado e conhecido milimetricamente. Nele, os médicos encontraram "explicações" não apenas para a primeira forma como as mulheres devem ser definidas, isto é, como "reprodutoras", mas também os indícios que explicitariam desvios em sua conduta, moralidade, psiquê, sentimentos e emoções (MARTINS, 2004, p.14-16). A ginecologia teve como efeito "racionalizar a sexualidade feminina e transformar 
seu corpo em um objeto analisável, mensurável e sujeito a diversas práticas de objetivação". 0 corpo da mulher foi associado a sua identidade e esta ao desempenho das "funções sagradas de esposa e mãe como um dever sagrado e natural" (MARTINS, 2004).

Esse cenário desencadeou estratégias facilitadoras para o universo médico. A mulher em trabalho de parto passou a se deitar para que o médico tivesse uma visão do canal vaginal por onde o bebê sairia. Essa posição, boa para o médico observar, mas ruim e dolorida para a mãe e o bebê, levaram a criação de novos procedimentos como o uso de fórceps e corte da vulva e vagina como rotina e desnecessariamente (episiotomia e a episiorrafia), medicações e tantas outras práticas hoje reconhecidas como desnecessárias e violentas. As transformações nas práticas do parto envolvem relações de poder que, sob o ponto de vista aqui defendido, as práticas de controle, dominação e resistência atravessam, em múltiplas direções, o relacionamento entre médicos, parturientes e demais profissionais envolvidos, apesar da posição desigual que cada um ocupa.

Portanto, tratamos de uma prática social em que as mulheres se encontram em "situação de violência" e isso nos leva a destacar dois aspectos que são afirmados por Santos e Izumino (2005). O primeiro é sobre a importância em relacionar cada caso e contexto "não apenas a questões de gênero, como também de classe social, raça/etnia e orientação sexual, entre outras categorias socialmente construídas". As autoras lembram que, ao serem atendidas pelas mais diversas instituições, inclusive as da saúde, não é do mesmo modo que são tratadas prostitutas, mulheres negras, mulheres pobres, travestis, brancas, de classe média.

São citadas as práticas de violência verbal, física e emocional, expressas desde negligências até abusos sexuais, de modo que as mais recorrentes são: toques abusivos, exposição física, banalização da dor, violências verbais e humilhação, corte da vulva e vagina, uso abusivo de ocitócitos para induzir o parto, a manobra de Kristeller, entre outras.

É na tentativa de se resguardar a integridade física, o direito ao próprio corpo, o nascer com respeito e o caráter fisiológico do nascimento, que o conceito de "parto humanizado" é retomado na atualidade. De modo geral, ele pode ser entendido como aquele que "procura garantir à mulher a preservação de seus direitos para um nascimento o mais natural possível. (...) os desejos da mulher são respeitados e acontece um amparo emocional, encorajamento e estratégias de diminuição da dor (OLIVEIRA; MADEIRA, 2002)".Para que o parto humanizado aconteça dentro do atual cenário hospitalar se faz necessária a ação de uma equipe que, através de uma formação ética e em saúde bem informada, se posicione em relação ao seu valor, ao sentido que Ihe atribui e o viabilize. Tal assistência nem sempre é possível no sistema público de 
saúde e nem garantida no sistema da maioria dos planos de saúde particulares, visto que não ofertam condições financeiras para que o médico abandone seu consultório repleto de pacientes para dispor das horas que demandam um trabalho de parto (DIAS, 2011). A cada dia mais se evidencia como fundamental a presença das doulas para garantir e preservar os direitos da mulher. Estas são mulheres que estudaram sobre nascimento, parto e sociedade e fazem o acompanhamento desde o pré-parto, atuando no suporte emocional à gestante e oferecendo uma garantia, frente à instituição hospitalar, de que seus direitos e vontade serão respeitados.

O parto humanizado também envolve o direito do recém-nascido sofrer o mínimo de interferências possíveis. Estes, assim que nascem, são submetidos a uma série de procedimentos que, na maioria das vezes, são inúteis ou passíveis de espera. As providências que se esperam em tal situação são: o direito a amamentação na primeira hora de vida, recomendado pela Organização Mundial da Saúde, tendo em vista diminuir as chances de desmame precoce; a espera que o cordão umbilical pare de pulsar antes de ser cortado, a não separação do recémnascido de sua mãe, possibilitando que se aqueça no calor de seu colo.

Como o Brasil se tornou um país recordista em número de cesáreas, chegando a ser considerado um quadro de epidemia, não apenas mães passaram a se mobilizar, mas todos os órgãos responsáveis pelo atendimento à saúde da população (BALOGH, 2013). As decisões sobre a necessidade do parto normal ou de outro tipo de intervenção é algo que exige cuidadosa atenção e preparo para lidar com escolhas e posições diversas. Para que as mulheres possam avaliar e reconhecer qualquer forma de tratamento violento e coercitivo, bem como os seus direitos, é necessário que tenham acesso a discussões e conhecimentos mais aprofundados sobre o assunto.

\section{CONSIDERAÇÕES FINAIS}

Até este momento, é evidente a ausência destes temas nos currículos voltados a formação em sexualidade dos jovens, sendo que grande parte das orientações dirigidas à esse público se pauta na ideia da não procriação como norma. Como parece que toda orientação é no sentido de que os jovens não procriem, também não se orienta (seja para o presente seja para o futuro) para o caso de ocorrer a gravidez. Desconsidera-se que ela pode ser também desejada ou valorizada por estes jovens, enquanto parte de seus processos de construção de autoestima e realização pessoal, tal como vem sendo verificado em algumas pesquisas. Assim, o principal alvo dos programas de educação em sexualidade continua voltado para o tratamento dos métodos contraceptivos e de proteção à saúde sexual, pouco se falando sobre os saberes dos direitos relativos à reprodução. Isso impede que os jovens tenham uma formação que os prepare para 
tomar decisões responsáveis e exigir um tratamento digno e respeitoso em suas possíveis experiências com a gravidez, a gestação, o parto e o exercício da maternidade e paternidade.

Tomar o parto humanizado e a violência obstétrica enquanto temas educacionais relevantes, que fazem parte da formação sobre os direitos reprodutivos dos jovens, implica partir de uma visão ampla e positiva da vivência da sexualidade juvenil, englobando aspectos diretamente relacionados aos desejos, sonhos e prazeres dos sujeitos, o que exige o cumprimento de seu direito a formação e informação sobre tais assuntos.

Defendemos que a temática da violência obstétrica e as discussões sobre o parto humanizado façam parte dos processos educativos, posto que a escola é compreendida como um local que contribui ativamente para a construção de subjetividades e identidades sociais. Com todas as suas contradições, ela é um lugar possível e potencialmente capaz de legitimar ou questionar as desigualdades e violências que organizam a vida social.

\section{REFERÊNCIAS}

BALOGH, G. Cultura cesarista faz sobrar vagas em casas de parto. Folha de São Paulo, Disponível em: $\quad<$ http://maternar.blogfolha.uol.com.br/2013/09/26/cultura-cesarista-faz-sobrar-vagas-emcasas-de-parto/> Acesso em: 29 set, 2013.

CABRAL, C. S.; HEILBORN, M. L. Educação integral em sexualidade dos jovens: da Conferência do Cairo aos dias atuais. In: Oficinas de trabalho, 2010, Brasília. Rumos para Cairo +20: compromissos do governo brasileiro com a plataforma da Conferência Internacional sobre População e Desenvolvimento. Brasília: Cidade Gráfica, v.1, 2010.

DIAS, M. A. B. Resenha: Humanização do parto: política pública, comportamento organizacional e ethos profissional. Maia M.B. Rio de Janeiro: Editora Fiocruz; 2010.Cad. Saúde Pública, Rio de Janeiro, 27(5):1041-1044, mai, 2011.

GAMA, A. S.; BARBOSA, G. P.; ORSI, E.; GIFFIN, K. M.; TUESTA, A. A. Representações e experiências das mulheres sobre a assistência ao parto vaginal e cesárea em maternidades pública e privada. Cad. Saúde Pública, Rio de Janeiro, 25(11):2480-2488, nov, 2009. Disponível em: http://www.scielo.br/pdf/csp/v25n11/17.pdf > Acesso em: 27 out, 2013.

MARTINS, A. P. V. Visões do feminino: a Medicina da mulher nos séculos XIX e XX. Rio de Janeiro: Editora Fiocruz, 2004.

MOREIRA, M. de F. S.; TORRES, T.L.M.; COLETO, M. G. Direitos reprodutivos e educação: abordagens, reflexões e pesquisas. In: RIBEIRO, A. I.M.; PRADO, V. M. do (Orgs.). Falando sobre gênero e sexualidades na educação: vamos nos permitir? Curitiba: CRV Editora, 2013.

OLIVEIRA Z.M.L.P., MADEIRA, A.M.F. Vivenciando o parto humanizado: um estudo fenomenológico sob a ótica de adolescentes. Revista da Escola de Enfermagem USP 2002; 36(2):133-40. Disponível em: <http://www.scielo.br/pdf/reeusp/v36n2/v36n2a04.pdf> Acesso em: 27 set, 2013. 
SANTOS, C. M., IZUMINO, W. P., Violência contra as mulheres e violência de gênero: notas sobre estudos feministas no Brasil. Revista Estudios Interdisciplinários de America Latina y El Caribe. Israel: Universidade de TelAviv, v.16. n.1, p.147-164, 2005.

SCAVONE, L. Dar e cuidar da vida: feminismo e ciências sociais. São Paulo: UNESP, 2004.

TONELI, M. J. F. Direitos sexuais e reprodutivos: algumas considerações para auxiliar a pensar o lugar da psicologia e sua produção teórica sobre a adolescência. Psicologia \& Sociedade, n.16, 2004.

VENTURA, M. Direitos reprodutivos no Brasil. São Paulo: Fundação Mac Arthur, 3ạ ed., 2009. Disponível em: <http://www.generoracaetnia.org.br/publicacoes/Direitos\%20Reprodutivos\%20no\%20Brasil\%203 \%C2\%AA\%20Edi\%C3\%A7\%C3\%A3o.pdf>. Acesso em: 01 abril 2011. VIANNA, A.; LACERDA, P. Direitos e políticas sociais no Brasil: mapeamento e diagnóstico. Rio de Janeiro: CEPESC, 2004. 